\title{
Spotlight on the March 11 Issue
}

\author{
Robert A. Gross, MD, PhD, FAAN \\ Editor-in-Chief, Neurology ${ }^{\circledR}$
}

Infarct hemisphere and noninfarcted brain volumes affect locomotor performance following stroke

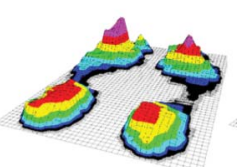

Left infarct

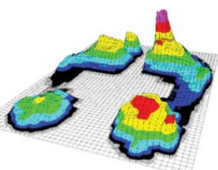

Right infarct

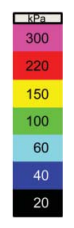

Right middle cerebral artery (MCA) infarcts, as compared to left, appear to be more detrimental to locomotor control. In these patients, greater cerebellum and caudate gray matter volumes correlated with faster walking speeds. Following right MCA infarction, locomotor control may therefore depend on the function of regions distant to the infarct site.

See p. 828; Editorial, p. 822

Neuroimaging abnormalities in adults with sickle cell anemia: Associations with cognition

This study determined the relationship of frontal lobe cortical thickness and basal ganglia volumes to measures of cognition in 120 participants with sickle cell anemia and 33 controls. The findings suggest that basal ganglia and thalamus abnormalities may represent a particularly salient contributor to cognitive dysfunction in adults with sickle cell anemia. See p. 835

Intracranial artery stenosis and progression from mild cognitive impairment to Alzheimer disease

This study evaluated clinical and neuropsychological examinations annually for 4 years in 423 participants with mild cognitive impairment. In addition to vascular risk factors such as hypertension and diabetes, intracranial arterial stenosis increased the risk of developing Alzheimer disease dementia following mild cognitive impairment.

See p. 842

PRECREST: A phase II prevention and biomarker trial of creatine in at-risk Huntington disease

The authors examined safety, tolerability, and biomarkers during a trial of high-dose creatine with $50 \%$ at-risk patients who did not want genetic testing. Structural MRI demonstrated slowed atrophy at the end of the 6 months of the double-blind phase and again at the end of 12 months of open-label treatment, suggesting disease modification. See p. 850

From editorialists McCusker \& Myers: "If we were to regard neurodegenerating cells as we do cancer cells, there would be immediate action at the first sign of disease. Definition of the prodrome is well advanced, but further refinement of the tools for staging the prodrome can be expected."

See p. 824
Submandibular gland needle biopsy for the diagnosis of Parkinson disease $[0$

Patients with Parkinson disease underwent a core needle biopsy of the submandibular gland. Of those with adequate glandular tissue, the majority had $\alpha$-synuclein staining. These findings suggest that performing a core needle biopsy of the submandibular gland is feasible and may be a possible tissue diagnostic test for Parkinson disease.

See p. 858; Comment, p. 862

Interaction between adolescent obesity and HLA risk genes in the etiology of multiple sclerosis OPEN

Two case-control studies, one Swedish and one American, present striking interactions between adolescent obesity and HLA genotype with regard to multiple sclerosis (MS) risk. The obesity epidemic may explain part of the increasing MS incidence as recorded in some countries. Measures taken against adolescent obesity may be a preventive strategy against MS.

See p. 865 ; Editorial, p. 826

Neurofascin IgG4 antibodies in CIDP associate with disabling tremor and poor response to IVIg

Immunocytochemistry identified antibodies to neurofascin 155 (NF155) and 186, with 2 of 53 patients having NF155 antibodies but none of 204 controls. The presence of distal weakness, slow action tremor, and lack of response to IVIg in chronic inflammatory demyelinating polyradiculoneuropathy should prompt the search for anti-NF155 antibodies.

See p. 879

\section{GLOBAL PERSPECTIVES}

\section{Improving the consent process for neuroepidemiologic research in resource-poor settings}

These investigators discovered that $44 \%$ of participants in a recent neuroepidemiologic study did not clearly understand that they were free to refuse participation. Consent forms for research in developing nations must be crafted to meet the individual and cultural needs of the participants.

See p. 895

NB: "Multicystic demyelinating myelopathy: Widening spectrum of pediatric aquaporin-4 autoimmunity," see $p$. 902. To check out other Neurolmages, point your browser to Neurology.org. 


\section{Neurology}

\section{Spotlight on the March 11 Issue}

Robert A. Gross

Neurology 2014;82;821

DOI 10.1212/WNL.0000000000000229

\section{This information is current as of March 10, 2014}

\section{Updated Information \&}

Services

Permissions \& Licensing

\section{Reprints}

including high resolution figures, can be found at: http://n.neurology.org/content/82/10/821.full

Information about reproducing this article in parts (figures,tables) or in its entirety can be found online at:

http://www.neurology.org/about/about_the_journal\#permissions

Information about ordering reprints can be found online:

http://n.neurology.org/subscribers/advertise

Neurology ${ }^{\circledR}$ is the official journal of the American Academy of Neurology. Published continuously since 1951, it is now a weekly with 48 issues per year. Copyright () 2014 American Academy of Neurology. All rights reserved. Print ISSN: 0028-3878. Online ISSN: 1526-632X.

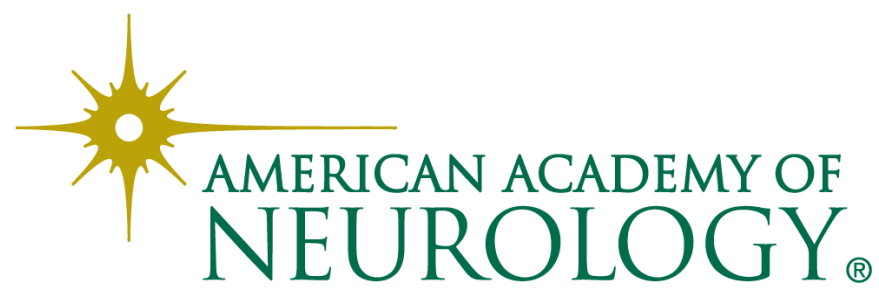

